\title{
El realismo político y su presencia y eficacia en la acción internacional
}

\section{Political realism and their presence and effectiveness in the international action}

Recibido: 16/02/2014 Aprobado: 04/09/2014

\section{RESUMEN}

El presente artículo, ofrece un análisis trasversal sobre la implementación del realismo político durante la Guerra Fría, en el contexto de un sistema bipolar. Para ello se revisaron los diversos enfoques y planteamientos de autores clásicos y modernos expertos en dicha materia; y se efectuó un análisis sobre la forma en que esta teoría fue llevada a la práctica por Estados Unidos, en sus decisiones de política exterior durante la guerra fría.

\section{PALABRAS CLAVE}

Realismo, Estado, moral, ética, intereses, legitimidad.

\section{ABSTRACT}

The present article offers an analysis trasversal on the implementation of the political realism during the Cold War, in the context of a two-pole system. For it there were checked the diverse approaches and expositions of classic and modern authors expert in the above mentioned matter; and an analysis was effected on the form in which this theory was taken to the practice by The United States, in his decisions of exterior politics

\section{KEYWORDS}

Realism, State, mulberry tree, ethics, interests, legitimacy.

1.- El autor agradece la colaboración de los profesores Carlos Zorro Sánchez (Universidad de los Andes); Nicolás Botero (Universidad Santo Tomás) y Hernán Olano (Universidad de La Sabana), por sus aportes para la construcción dialógica del presente texto. 


\section{INTRODUCCIÓN}

En desarrollo de la línea de investigación en <<Pensamiento hegemónico y subalternidad >> del Grupo de Investigación "Sociopolítica, Ambiente y Análisis Cultural" de la Universidad de La Sabana, se pretende generar modelos interpretativos que contribuyan al fortalecimiento del orden político, los derechos humanos, la cultura de la paz, la sana vida democrática, la superación de la violencia, la anomia social, la pérdida de la identidad cultural, así como el deterioro del medio ambiente en Colombia; uno de ellos es el desarrollo, presencia y eficacia del realismo político en el contexto internacional.

El realismo político es una de las tradiciones de pensamiento en las relaciones internacionales; apunta al mundo del poder y la seguridad, tal "cómo es" en perjuicio del "deber ser", más cercano al ideal de la política. Muchas acciones se pueden entender y justificar desde la perspectiva realista. Cuando los intereses nacionales entran en contradicción con los principios y normas que dicta la ética y la moral vigente, se recurre a la razón de Estado. Dado su pragmatismo, este tipo de enfoque se ha posesionado como el más relevante dentro de las interpretaciones existentes, a nivel mundial; de esta forma, la realpolitik guía el accionar de muchos gobiernos en el ámbito exterior. La tenencia y el aumento del poder son las aspiraciones comunes del cualquier gobierno por más pequeño que este sea.

Dado lo anterior, en el presente artículo se intenta explicar si los criterios de tipo moral le restan eficacia a las decisiones en política internacional; es decir, se aborda una cuestión ampliamente controvertida, en cuanto a prioridades: si la elección éticamente correcta, por parte de un Estado; o la implementación de estrategias acordes con los intereses nacionales del mismo.

En la primera parte, el artículo revisa los principales autores del realismo clásico y moderno, sus planteamientos y la forma como en algunos Estados la teoría realista se expresa en el proceso de toma de decisiones en política exterior. En una segunda, se describen los hechos más importantes del realismo que tuvieron lugar durante la guerra fría, más exactamente, los que condujeron a la competencia que existió entre el bloque del este y oeste. Finalmente, se abordan los planteamientos que se alejaron del realismo por privilegiar los criterios morales, durante el mismo período.

\section{LEGITIMIDAD Y ANARQUÍA EN EL SISTEMA INTERNACIONAL}

El realismo es el paradigma central de las relaciones internacionales; las restantes tradiciones se han desarrollado como alternativas de su hegemonía intelectual. A través de ejemplos históricos podemos identificar esta disyuntiva entre acciones políticas y moral internacional.

El manejo de las relaciones internacionales efectuado por las grandes potencias mundiales a partir de la caída del Muro de Berlín y cómo éstas se han justificado satisfactoriamente aplicando los criterios morales y éticos, es una pregunta legítima que preocupa. Correlativamente surge la duda de cómo se diseña una política exterior funcional y eficaz pero que respete preceptos morales y éticos sin perder la eficacia. El realismo carga con el estigma histórico de que el fin justifica los medios privilegiando el fin y no las herramientas para conseguirlo.

En un mundo donde los intereses nacionales y el poder orientan las políticas exteriores, es muy difícil separar lo justo de lo legítimo cuando esto último depende de la "Razón de Estado", como lo decía Richelieu; entonces, pareciera que podrían ir siempre de la mano, pero no todo lo legítimo es siempre justo diría un realista convencido.

Ahora bien, al hablar de la razón de Estado, está se relaciona con los fines esenciales y los intereses de ese Estado que se impone y predomina en lo justo o injusto que pueda ser una acción. Esa justificación estará dada por las ideologías del gobierno de turno como también por la moralidad que maneje éste.

La naturaleza anárquica del sistema, la cual está 
dada por la inexistencia de una autoridad central y jerárquica, que sea reconocida por todos, dificulta el proceso de toma de decisiones internacionales. El conflicto forma parte del sistema y eso hace que muchas decisiones que podrían reñir con lo moralmente aceptable, sean totalmente legítimas, amparadas por los incuestionables intereses nacionales que predominan en última instancia. Para Maquiavelo, las consideraciones morales en los temas de estado carecen de importancia y que el poder y la moral son mutuamente excluyentes. Sobre lo mismo, Max Weber sostenía que el realismo justificaba el cinismo y la inmoralidad, "quien quiera salvar su alma debe alejarse de la política."

\subsection{Autores clásicos y modernos}

En la historia se destacan Tucídides, Maquiavelo y Hobbes, como autores protagónicos separados por tiempo y distancia pero muy significativos para el realismo (Ortiz, 2000. pp 100-111). Aunque la obra de Tucídides no es política se destacan los pasajes donde menciona la imposibilidad de evitar el conflicto entre Atenas y Esparta como también su Debate Meliano (citado en Vásquez, 1994, p.36).

El internacionalista español Celestino del Arenal (2002), de manera sucinta define al realismo como un paradigma práctico de pesimismo antropológico que rechaza la posible armonía de intereses estableciendo que el conflicto es consustancial al sistema internacional. El realismo asume que los principios morales en abstracto no pueden aplicarse a la acción política.

Esto queda claramente representado en los ejemplos históricos que se irán desarrollando como también el pensamiento exterior norteamericano de la guerra fría personalizado y representado por Henry Kissinger. Tiene un enfoque estatocéntrico al considerar al Estado como el actor fundamental de las relaciones internacionales cuyos objetivos se centran en el interés nacional y el poder donde predomina el conflicto, pues el mundo es esencialmente anárquico al no existir un poder ni una autoridad central fuerte.
Como bien apunta Carlos Zorro Sánchez en entrevista personal, el realismo político es la persistencia de la ley del más fuerte en el mundo contemporáneo, rezago de tiempos primitivos en que también se aplicaba a las relaciones entre individuos.

Ahora bien, desde el Realismo - Estructural 0 Neorrealismo, Waltz (1988) anotaba que los derrumbes de las ideologías y utopías de la política internacional hacia resurgir con más fuerza el realismo político. Su vitalidad se vincula con claves de sobrevivencia de los Estados. En ese sentido se habla de paradigmas, cómo el statu quo, la anarquía, el equilibrio del poder y la prudencia de los Estados, el que aconseja prudencia al poderoso y cautela al débil.

Sin embargo, el concepto de anarquía, tal y como lo propone Waltz (1988), plantea múltiples desafíos en la nueva organización de los sistemas y subsistemas, aquellos que pueden subsanar algunos hechos que se han planteado, como la solución a la relación entre las diferentes unidades o (Estados) y sus relaciones. Estos desafíos se presentan de manera permanente en el desarrollo de las políticas interna y exterior de los Estados en el mundo contemporáneo, debido a su deseo por consolidarse en los escenarios internacionales y, que hasta el momento han tenido muchos intentos y poco resultados.

Por lo tanto, al hacer referencia al Neorrealismo y principalmente a Waltz, el primer referente es el concepto que se tiene de la cooperación de los Estados, el cual se explica, como la capacidad que tienen los Estados para trabajar de manera mancomunada, con la intención de mejorar las capacidades de todos los que cooperan, en vez de preocuparse tanto por los beneficios que cada uno quiera obtener. Esto permite resaltar el concepto al que el autor se refiere como el de interés común de los Estados (Waltz 1988, p.106).

En ese orden de ideas, es claro que la visión realista tiene una concepción hobbesiana de las relaciones internacionales. Sin embargo, Hobbes por su parte, sostiene en su estado de naturaleza un caos que 
antecede a la sociedad políticamente organizada y muestra a un hombre egoísta y pesimista que necesita de la coacción de la ley para su organización y regulación. Ese ente regulador llamado Estado, tampoco garantiza la armonía pues está regulado por la fuerza, la violencia y el egoísmo. Esta etapa de las cosas es asimilable al contexto internacional en donde prevalece el desorden y la anarquía. (Ortiz 2000, pp. 100 - 111). Hobbes plantea la imposibilidad de una justicia global sin que exista también un gobierno global-(Sen 2009, p. 57).

De acuerdo con Carr (1964), Maquiavelo, el primer realista de tradición occidental, (Sin dejar de lado a Guicciardini), (Olano 2014), hablaba de la supervivencia de ese Estado por sobre los derechos individuales y colectivos. Pueden considerarse totalmente legales pero también ilegales como atentar con la vida o el terrorismo de Estado si se da el caso, teniendo en cuenta que, en muchos casos, ha sido usado como pretexto para justificar acciones de ética cuestionable. Quizás por ello, la razón de Estado posee mala reputación, pues podría llegar a validar acciones ilegítimas e ilegales de un gobierno para mantener el statu quo o invalidar a sus contradictores. La legalidad al igual que la tradición y el carisma son fuentes de legitimidad para un poder político.

La legitimidad tiene varias vertientes, la legal tradicional y carismática. La legal responde a la ley como origen del poder en cuanto a facultades, tiempo y limitaciones, requisito obvio en cualquier regimen democrático; la carismática tiene que ver con los atributos personales que reforzarian el liderazgo; Ghandi en India es el ejemplo, y por último, la tradicional tiene relacion con las costumbres, tradiciones que van fortaleciendo un liderazgo como las monarquías 0 algunas normas consuetudinarias que facilitan la escogencia de un líder en algunos pueblos sin mucho desarrollo político. El realismo en Estados Unidos, se manifiesta con gran intensidad después de la segunda guerra mundial, cuando van surgiendo representativos intelectuales como Hans Morgethau, George Kennan, Henry Kissinger y Zbigniew Brzezinski.
Por eso, antes de pensar en el "cómo", pensar en el "qué" y tratar de definir qué enfoque ético es privilegiado por el realismo en las relaciones internacionales y si ese enfoque es el más adecuado desde la perspectiva humana y qué implicaciones tendría la aplicación del Realismo en las relaciones internacionales.

Una interrogante que surge es la posibilidad que en el mundo contemporáneo se diseñé y apliquen políticas exteriores eficaces que respeten principios éticos y si estos coinciden con los principios morales que prevalecen en la política internacional y cómo explicar lo ético y moral en las relaciones internacionales a través de la conducta de algunas potencias que continuamente transgreden estos elementos. La autonomía de la esfera política frente a la esfera ética no significa que estemos frente a una teoría inmoral, sino que la moral, en tanto que objeto de las relaciones internacionales, queda fuera de estudio. (Palacio de Oteyza, 2003, p. 9).

\subsection{Marco teórico de Peltz}

Stephen Peltz sostiene por su parte que en las relaciones internacionales siempre ha existido un alto grado de anarquía; cada Estado intenta extender su poder frente a los demás para asegurar al máximo territorios y potencial industrial. La defensa 0 protección de las áreas vitales es un problema de seguridad por lo que se debe incrementar el poderío militar y las alianzas. (Peltz, 1991).

Según este autor, cuando el equilibrio se produce y es estable se debe analizar la estructura de las alianzas, la existencia de afinidades ideológicas y los procedimientos para dirigir y manipular los cambios. Este último mecanismo es la diplomacia por si la balanza se inclina a una de las potencias, los Estados afectados intentaran negociar para reestructurar alianzas y concesiones que restablezcan el equilibrio (Arroyo 1999, p. 117).

Según el autor, las relaciones internacionales están sujetas a cambio de status y poder entre los Estados por alguna revolución social que cambie el status 
social o político en uno o más actores claves del sistema, también la tecnología que crea nuevos métodos militares o tecnologías que puedan afectar el sistema y una desigualdad del desarrollo económico y tecnológico entre las grandes potencias que ocasionen cambios de liderazgo. Así las cosas, las revoluciones políticas, militares, económicas y tecnológicas cambian las reglas como al propio sistema.

\subsection{El realismo político desde la visión de Hans Morgenthau}

Este es el más reconocido realista norteamericano, que intenta formular una teoría en la que no distingue entre política interna e internacional. Su modelo apunta a la guerra fría y si quisiéramos resumir sus tópicos fundamentales, se destacan la concepción pesimista del hombre y de la política, la centralidad y el equilibrio de poder, así como el interés nacional como el principal objetivo de la política exterior, junto con la inexistencia de criterios morales en la política internacional y el interés exclusivo en el poder y la forma de aumentarlo.

Estos principios determinarán el comportamiento de los Estados y las leyes que imperan en el orden internacional del sistema, cómo se mantienen o alteran los equilibrios $y$, el papel fundamental que juegan las súper potencias en este sistema competitivo.

El realismo político según Morgenthau reconoce la existencia de imperativos éticos universales pero no necesariamente encajan mecánicamente en el mundo político, ellos deben ser adaptados de manera flexible dependiendo de la coyuntura. El realismo político afirma que los principios morales universales no pueden ser aplicados a las acciones estatales en su formulación universal abstracta, sino que deben ser filtrados a través de las circunstancias concretas de tiempo y lugar. (Oro Tapia, 2009, p. 31).

Los tópicos más fuertes del realismo desde la visión de Morgenthau, serían que las relaciones políticas son gobernadas por reglas objetivas enraizadas en la misma naturaleza humana e igual a lo que dicen ciertos economistas los hombres de Estado piensan y actúan en términos de interés y este se define como poder y se comprueba científicamente a través de la historia. El realismo resalta el significado moral de la acción política pero también conoce de la tensión entre las conductas morales y los requisitos de una acción política triunfante, y se niega a establecer una relación entre las aspiraciones morales de una nación en particular y los preceptos morales que rigen el universo, además mantiene su autonomía en la esfera política y no ignora los parámetros de pensamiento distintos a los políticos.

Morgenthau sostiene que el realismo político es consciente de la importancia de la moral en el poder político (citado en Vásquez, 1994, p. 55), pero también entiende la tensión que surge entre los mandamientos de la moral y las exigencias de un poder político exitoso. El realismo cree que es difícil aplicar principios morales universales a los actos estatales.

\subsection{La guerra fría y el realismo político de George Kennan}

Según este autor, se deben separar los planteamientos teóricos de la acción real llevada a cabo por el ejecutivo. Teoría y práctica se unen al igual en Kennan y Kissinger, y representa al realismo en el período de posguerra, agregando elementos al pensamiento de Morgenthau. Cabe destacar la importancia que el autor le dará a la política de poder por parte de EEUU rechazando cualquier influencia legalista 0 moral que restaría poder frente a un Estado expansionista como la URSS.

Hay dos ideas básicas que expresan claramente el pensamiento de Kennan, por una parte la preponderancia del interés nacional como última palabra evitando las interpretaciones ideológicas. La contención de la expansión comunista como la meta de la política exterior norteamericana en su papel de pueblo escogido debe equilibrar el poderío soviético mediante el control de zonas de influencia. 


\subsection{La política exterior ¿un caso de Ética moral?}

La pregunta que surge es ¿Cómo sería una política exterior ligada a la moral o a lo considerado moralmente bueno? ¿Funcionaria?

Lo moral se refiere al comportamiento según la fe que siente cada quien y esto no obligatoriamente involucra lo religioso. Puede existir moral cristiana, moral musulmana etc., en cambio ética son las buenas prácticas de comportamiento en los diferentes campos de la vida en comunidad. Los mandamientos de carácter moral y religioso consideran ante todo el acto o momento interno, el yo del individuo, la bondad o maldad del impulso que ha determinado la acción, sin que estén encaminados directamente a regular relaciones de intereses individuales o colectivos ni a crear derechos, pues su influjo tiende a que cada ser humano procure sentir y obrar conforme al ideal ético o religioso que constituye la razón enaltecedora de su fe, o, en términos generales, de la moral (Olano, 2008).

Uno de los peligros de la política exterior, sería entonces, enfocarnos en las características de la organización política occidental e intentar imponerlas como enfoque general de justicia y equidad en el mundo (Sen, 2009, p. 58). Los orígenes del idealismo en occidente se remontan a la tradición de las guerras justas, basadas en un razonamiento ético judío cristiano al afirmar que la política exterior debe promover el bien.

A comienzos de siglo XX se fue incorporando la idea de que las guerras se debían a los ardides y la política del poder como a los intereses de líderes no democráticos, por lo que la solución era la transformación de estos factores y hacer prevalecer la razón en la coyuntura internacional para hacer desaparecer la irracionalidad de la guerra. Había una fuerte relación entre el uso de la razón y la inexistencia de conflictos (Vásquez, 1994, p.20).

El presidente norteamericano Woodrow Wilson fue un gran protagonista del idealismo político y por ello creo la Liga de las Naciones para impedir agresiones y herramienta de solución pacífica de conflictos, aunque la historia indicaría lo idealista y utópico de este proyecto. En este ambiente nacen las relaciones internacionales como ciencia independiente separándose de la historia de la diplomacia y la filosofía con las cuales se confundía. (Sanhueza, 2003). De utópicos e idealistas fueron calificados estos autores por los realistas, el enfoque de Razón de Estado terminó siendo impuesto frente a consideraciones morales donde el Estado queda exento de moralidad ya que esto lo debilitaría.

De acuerdo con Sanhueza, (2003), los elementos que aportan a esta escuela son la relevancia de la historia, la función central del Estado, acción estatal, anarquía internacional y la restricción de la cooperación internacional. El acento en la historia enfatiza que el mundo moderno es una simple continuación del antiguo, pese a su innegable avance tecnológico los antiguos lo podrían haber entendido y analizado perfectamente. El realismo es bastante escéptico con la naturaleza humana pero busca en los hechos históricos explicaciones al que hacer actual, se puede analizar y sistematizar la política internacional usando datos históricos.

El carácter Estatocentrico, se ve claramente reflejado desde el realismo en el actor protagónico de la política internacional, sin desconocer a otros actores como organismos internacionales, ONGs y multinacionales; pero el Estado fija las pautas por donde se desarrollará el acontecer internacional y condicionan a los restantes actores. Para Sanhueza, (Sanhueza, 2003, p. 407), el Estado es un actor racional, autónomo y unitario, que tiene objetivos prefijados y conforme a ellos traza su acción internacional como la estrategia y los costos para alcanzarlos.

En el sistema internacional, los Estados actúan en un entorno anárquico, que toma el significado de la ausencia o inexistencia de una autoridad central que aplique protección o a la cual exigirle reparación. El ambiente internacional es incierto y peligroso (Sanhueza, 2003, p. 408), lo que implica que los Estados deben subsistir y protegerse, ya que son actores defensivos que continuamente se comparan 
con otros y basan sus acciones sobre el mismo interés nacional.

Para el autor español Palacio de Oteyza (2004), desde la guerra fría, el realismo político se sostiene sobre unos elementos comunes que varían dependiendo del autor y de la escuela. En este caso el power politics o la concepción política del poder y su omnipresencia. Esto no implica autoritarismo en vez de democracia, sino que regímenes demo liberales le den relevancia al poder en sus relaciones internacionales.

El Estado para la escuela realista, se caracteriza por ser un actor racional, cuyo elemento central está dado por las relaciones competitivas y de poder que existen entre ellos, refiriéndose a los planos económicos, tecnológicos y militares, antes que centrarse en las relaciones entre los individuos. Es de resaltar, que los Estados, no siempre buscan maximizar su acción sino conservarlo, particularmente el Poder militar, que por sobre los otros elementos, y sobre las potencias, puede convertirlo en poder económico y viceversa.

El realismo utiliza el equilibrio de poder para fortalecer el poder frente a la seguridad colectiva y el gobierno mundial. El equilibrio de poder y su dinámica como elemento recurrente de la política exterior independiente de sus motivaciones. La primacía de la política internacional sobre la actividad económica.

Estas esferas deben permanecer distanciadas. En la historia de las relaciones internacionales del siglo $X X$, ha habido experiencias muy asociadas al realismo, una de ella es la distensión entre EEUU y la URSS en plena guerra fría tras la crisis de los misiles en 1962. Esta crisis fue un conflicto entre ambas potencias generado a raíz del descubrimiento por parte de EEUU de misiles nucleares soviéticos en la isla de Cuba. Este hecho histórico fue desde el principio de la guerra fría, el acontecimiento más cercano a una hecatombe nuclear y llevo, paradójicamente, por puro realismo político, al acercamiento y relajamiento de las relaciones entre
EEUU y la URSS que concitó a las potencias a un período de distensión cuyo principal argumento se basaban en las armas para ser mostradas no para ser usadas, no querían destruir el mundo sino repartirlo.

La distensión fue un esquema realista de relaciones internacionales encaminado a abrir crecientes canales de comunicación, entendimiento, intercambio y cooperación entre países con regímenes políticos distintos pero que a través de la negociación y no del enfrentamiento pueden solucionar sus conflictos. Se reconocía un statu quo internacional fundado en el equilibrio de poder y una mayor y más activa participación de otros actores internacionales que buscasen las soluciones de compromiso sin recurrir a la fuerza. (Valdes, 1987).

No implicaba el término del conflicto ni que las potencias dejen de pugnar entre sí, sino un acuerdo tácito acorde con las circunstancias internacionales imperantes. Más bien, poner un marco regulatorio, encuadrar las relaciones internacionales con ciertas reglas del juego cuyo objetivo final era evitar la guerra y los enfrentamientos permanentes. No era esa una visión utópica, sino más bien la aceptación de la realidad y un esfuerzo práctico para mantener bajo control al adversario. Un enfoque realista con el que se aprendía a convivir con el sistema internacional imperante sin intentar cambiar su estructura esencial.

Los respectivos bloques rechazaron los slogans ideológicos y las cruzadas morales típicas de la guerra fría. La URSS se cuidó de enfatizar que la distensión correspondía a un relajamiento de las tensiones entre las superpotencias y no un impedimento del determinismo histórico acerca de los procesos de liberación nacional a nivel mundial.

La distensión representa en la guerra fría una expresión fidedigna del realismo pues cada potencia tenía su propia visión de esta etapa conforme a unos intereses nacionales no transables.

La URSS quería consolidar su zona de influencia a 
partir de la ayuda económica internacional, a través de comercio y créditos. Permitir la flexibilización de los enemigos al favorecer fuerzas para el cambio social y económico fuera del control de EEUU y colocar las prioridades internas por encima de la externas en la agenda de los rivales.

EEUU, por su parte, aspiraba a una mayor flexibilidad mediante la creación de vínculos que hicieran a los soviéticos más dependientes de occidente y que el bloque democrático pudiese imponer un grado de disciplina a la URSS introduciendo el mundo exterior en el proceso político soviético.

\subsection{Henry Kissinger y la aplicación práctica del realismo en la guerra fría}

Henry Kissinger, el Secretario de Estado realista del presidente norteamericano Richard Nixon, fue el artífice de la distensión y gran revolucionario en la política exterior norteamericana (Kissinger, 1996). Su mérito era aunar conocimientos teóricos especializados y sentido práctico del quehacer político.

La distensión era un esquema de relaciones internacionales encaminado a abrir canales de cooperación y entendimiento entre países con regímenes políticos que privilegian la negociación por sobre el enfrentamiento. Era una expresión total de realismo político para evitar una hecatombe nuclear.

Kissinger también fue protagonista de esta escuela en la época más dura de la guerra fría. El basa su teoría en la necesidad de análisis históricos, en la revisión de los autores clásicos (Hobbes; Maquiavelo; Guicciardini) y la revisión de los postulados de Morgenthau. El diplomático judeonorteamericano, apunta sus teorías realistas a una nueva realidad vinculada a la era nuclear y la posibilidad de una real y pragmática negociación para evitar la guerra total y la hecatombe nuclear.

Según él, existen dos tipos de ordenes; el legítimo que apunta a un acuerdo tácito o expreso entre las superpotencias y uno revolucionario que habla de la inexistencia de un acuerdo sobre un tema o área determinada. De aquí surge su teoría de la disuasión (mientras más armas, más paz tengo) y las negociaciones de nucleares con la URSS.

Ahora bien, para Kissinger el orden estable solo podrá ser posible cuando se considere tres cambios en la política internacional: el número y la naturaleza de los miembros, su desarrollo tecnológico y el antagonismo político e ideológico.

En este clima de anarquía parece lógico que entre las herramientas de política exterior la diplomacia y las armas están al mismo nivel, por el poder disuasivo de estas. Sería interesante poder contestar algunas dudas que surgen en torno a este paradigma.

Antes de pensar en el "cómo", pensar en el "qué" y tratar de definir qué enfoque ético es privilegiado por el realismo en las relaciones internacionales y si ese enfoque es el más adecuado desde la perspectiva humana, y qué implicaciones tendría la aplicación de ese enfoque en las relaciones internacionales.

Su concepción de la política internacional estaba fundamentada en el globalismo y la coyuntura. Lo global responde a la elaboración de un modelo teórico frente al sistema internacional y la posición que EE.UU. debe ocupar en él, en cambio lo coyuntural apunta a la aplicación del modelo para abordar los problemas planteados por la situación interna y externa de EE.UU. en ese momento. (Valdes, 1987).

El realismo de Kissinger lo llevaba a plantear dos ideas fundamentales: la necesidad de integrar fuerza y diplomacia como imperativos de la política de poder y la contención especifica de la URSS. La suya era una búsqueda de una real política carente de discursos morales y de un espíritu de cruzada. Buscar un entendimiento mínimo en un sistema internacional estable era la única manera de evitar la guerra atómica. Solo se logra la estabilidad mediante un orden internacional legítimo y aceptable para 
ambas potencias de manera que no existan Estados insatisfechos en cuanto a la distribución del poder mundial que los obligue a tomar una política exterior revolucionaria en contra del statu quo internacional imperante.

Para Kissinger y el realismo, la legitimidad internacional puede o no coincidir con la justicia pero debe establecerse un consenso necesario de la comunidad de naciones sobre lo permitido y la naturaleza y los arreglos factibles entre sus miembros.

El principio de legitimidad no estaba dado por un acuerdo sobre los regímenes políticos, ni su orden social interno, sino por lo considerado tolerable en la conducta externa de los países. Se acepta cualquier modelo político y social con la única condición de un comportamiento internacional moderado y de acuerdo al statu quo establecido, esto define al realismo puro. Esta distensión realista de Kissinger intentaba estructurar un sistema de equilibrio de poder internacional capaz de conciliar los intereses nacionales de los principales miembros de la comunidad internacional. Era necesario para asegurar la coexistencia pacífica que se estableciera un equilibrio de poder entre las potencias que las obligara a restringir la exportación de sus creencias. En esto, Kissinger intentaba estructurar un sistema de equilibrio de poder que conciliara los intereses nacionales de los principales miembros de la comunidad internacional. (Cvitanic, 2014, p. 102).

Una analogía válida era la política europea aplicada en el Congreso de Viena en 1815 que daba legitimidad a un esquema de relaciones internacionales posterior al periodo revolucionario de Napoleón, esto se podía comparar con la situación post segunda guerra mundial y la distensión planteada por Kissinger.

Kissinger pensaba que la URSS, China y el mundo comunista estaban expuestos a un aburguesamiento, no solo en cuanto a su occidentalización sino a una tendencia a perder su carácter revolucionario. (Valdes, 1987, p. 114). Existían presiones de liberalización en lo interno y necesidad de apertura internacional en lo externo que debían ser aprovechadas por occidente.

En el campo de la seguridad internacional y el monopolio de armas atómicas resultaba fundamental una relación triangular entre Moscú- Washington Pekín y en el campo de la cooperación se necesitaba un sistema pentapolar entre EEUU, URSS, China; Japón y Europa Occidental.

El poder de negociación dependía del poder nacional que conjuga los factores físicos, económicos humanos y políticos para obtener un status en la comunidad internacional y la habilidad de los gobernantes para apreciar en la justa medida los objetivos de la otra parte.

Kissinger creía que solo la distensión realista podría brindar ventajas a EEUU en atención al deterioro de su poder nacional y al fortalecimiento proporcional de la URSS. EEUU al sostener una política de Statu Quo y URRSS una de carácter revolucionario el sistema debía sustentarse sobre la cooperación y no el enfrentamiento lo que era bastante realista en ese contexto de guerra fría. (Cvitanic, 2014, p. 101).

Según el internacionalista Pablo Valdés (1987), mientras EEUU tuvo superioridad numérica estratégica sobre las URSS no hubo problemas para mantener el sistema establecido y la contención, pero cuando las fuerzas nucleares se equilibraron aquella política disuasiva americana de defensa ya no fue efectiva pues la URSS se sintió más fuerte y psicológicamente más potencia también.

La disuasión se mantuvo como estrategia militar y nuclear no en el campo diplomático donde se buscó eludir la competencia directa con la URSS Ilevándola a un esquema de entendimiento global.

Tres cursos de acción se recomendaron a seguir por Nixon en plena guerra fría en las relaciones con la URSS.

Revivir la Comunidad Atlántica para integrar los 
intereses vitales de occidente por medio de una acción conjunta de EEUU, Canadá y Europa occidental; descongelamiento de las relaciones con China para neutralizar a la URSS; para evitar un desgaste de EE.UU en sus muchos compromisos internacionales se debería elegir unos socios menores para que tales estados defendieran los intereses americanos en el mundo a cambio de compensaciones económicas políticas o militares.

\subsection{Intervención y realismo: Nixon en las relaciones internacionales}

En plena Guerra Fría, Chile, un lejano país sudamericano sube al poder a un socialista marxista: Salvador Allende y hace sonar las alarmas en la Casa Blanca al presidente Richard Nixon y a su secretario de Estado Henry Kissinger. EEUU no podía permitir otro gobierno de izquierda con el agravante que a diferencia de Castro el de Allende tenía la votación popular que le daba mayor legitimidad que al régimen cubano.

Frente a esta peligrosa coyuntura había que actuar rápido e impedir que la vía chilena al socialismo prosperara y se propagara como ejemplo a los países vecinos. En este caso el realismo político del fin justifica los medios se aplicó totalmente influenciando y presionando a las fuerza armadas, empresariado, clase media, sindicatos, a levantarse frente al sistema, "ya que ese pueblo se equivocó hay que enmendarles el camino se escuchó en la oficina oval". (Uribe, 2002).

Los intereses norteamericanos en la guerra fría le daban legitimidad a un régimen dictatorial por Allende más allá si esto era justo 0 no, el origen democrático del régimen de Allende no importo mucho a la hora de tomar decisiones y defender intereses nacionales norteamericanos.

\subsection{El debate clásico Realismo vs idealismo}

Ante el fracaso y desilusión de los resultados del idealismo en la lucha estratégica con la URSS y su aplicación por Carter, surge el realismo como visión estática frente a la visión de progreso idealista, la concepción positiva de la naturaleza humana no llevaba a soluciones prácticas, una posición determinista del realismo contrasta con lo esperanzador del idealismo y la existencia de antagonismos no armónicos del realismo frente a la existencia de intereses complementarios idealistas llevaban al antagonismo de estos dos paradigmas.

\subsection{Anti realismo y moralismo de Carter}

El gobierno de Jimmy Carter (1976 - 1980), surge como una respuesta al desgaste del pragmatismo y realismo de la administración Nixon. Al gobierno de Carter se le asocia al moralismo y marca un nuevo estilo de hacer política exterior que es cuestionado por agregar idealismo en tiempos que no era aconsejable.

Sus resultados en política exterior estuvieron marcados por una coyuntura desfavorable como la revolución islámica y la llegada del Ayatolah Jomeini al poder en Irán, la invasión soviética a Afganistán y la toma de rehenes en la embajada de EEUU en Teherán que sin duda fue la más demoledora para impedir su reelección pues se lo asocio a una pérdida de poder americano en el mundo fruto de la debilidad de la administración Carter. Lo único destacable en este campo fue la firma de la paz entre Egipto e Israel que cambio la relación de poderes en esa conflictiva zona.

El realismo ya no tiene cabida para Carter y a través de un moralismo se buscaba recuperar el liderazgo norteamericano entre las naciones democráticas lo que debilitaba a EE.UU, pues muchos de sus aliados no tenían muchas credenciales democráticas. "No importa que sean malhechores, son nuestros malhechores". Una reformulación humana y moral de la política exterior no aconsejable para los tiempos de enfrentamiento y antagonismos entre potencias de guerra fría.

Carter intentó revitalizar la tradición moralista de EE.UU. resucitando el liberalismo y mostrándolo como una ideología más llamativa que el marxismo 
leninismo para los pueblos oprimidos del tercer mundo (Valdes, 1987, p. 191). Quizás si la dosis de realismo estuvo en enfocar el problema mundial y el conflicto entre sur y norte más que entre este y oeste.

Brzezinski asesor de seguridad de Carter profundiza el concepto de negociación elaborado por Kissinger no solo a la URSS sino también a sus relaciones con el tercer mundo. El gobierno de Reagan supuso un retorno a la ortodoxia realista volviendo a la intransigencia frente al comunismo y usando la influencia y la fuerza directa o indirecta para los conflictos del tercer mundo.

\subsection{Reagan y la década de los 80 s del siglo XX}

La década de los 80 del siglo XX, responde fielmente a algunos postulados de la escuela realista de la guerra fría como la universalización de las relaciones internacionales, el bipolarismo, las superpotencias rectoras, las zonas de influencia y los ciclos sucesivos de cooperación y enfrentamiento. La década de los 80 s presenta una realidad mundial en transición (Cvitanic, 2014, p. 110). La distensión se acaba con la invasión soviética a Afganistán porque significó arrojar al suelo las reglas del juego y los pactos tácitos entre las superpotencias. La invasión de la URSS desde el realismo político significo una alianza temporal y oportunista entre los norteamericanos y los talibanes frente a un enemigo común. Eran ateos para los afganos rebeldes y comunistas revolucionarios para los americanos.

Se cambia la era de la conciliación y cooperación internacional por la era de la confrontación y mayores tensiones. Hubo un renacimiento de la primera etapa de la guerra fría a comienzos de los 80 s por el término de esta distensión. Se cambió también el lenguaje y terminología, y aumentaron los embates ideológicos, disminuyendo los intercambios de alto nivel y las cumbres. Las relaciones entre EEUU y URSS sufrieron el mayor enfriamiento en los últimos veinte años.

Serios equívocos terminaron por desprestigiar la distensión, era obvio que las realidades del poder mundial terminarían imponiéndose a las buenas intenciones y al entendimiento pacifico de los Estados. Esta mala interpretación de la distensión llevo a deteriorar la relación de las potencias.

Este esquema llevo tal vez a EE.UU. a esperar mucho y pronto de la URSS de manera idealista cuando los soviéticos lo plantearon de manera realista solo como un modus vivendi basado es sus intereses nacionales, obtener mercados y tecnología de occidente como también limitar y controlar mediante acuerdos el desarrollo de armas norteamericanas, lo que llevo a que esta interpretación distinta deteriorara las relaciones entre las superpotencias.

La victoria de Reagan en dos mandatos consecutivos (1980 - 1988), marca el retorno republicano a la Casa Blanca y el deseo de recuperar el poder perdido ante la URSS en el período Carter. Se vuelve a la idea de contención frente a Moscú y se incrementan los gastos en defensa y la instalación de misiles en Europa occidental aumentando la presencia de la OTAN (Cvitanic, 2014, p. 114).

En este período se volvió a la época de acusaciones reciprocas, la URSS acusa de estar persiguiendo la superioridad militar y bajo esas condiciones no era posible sostener conversaciones con EE.UU., por lo que en 1983 se suspenden las negociaciones sobre armamento estratégico. El realismo sugería aceptar el status de súper potencia del otro y no cambiar su sistema social, el enfriamiento se daría solo en líneas generales.

Para la URSS., todo lo conseguido en la distensión se acabó con la llegada de Reagan por lo que no había más remedio que producir un ambiente de tensión para obtener concesiones. La vía diplomática en esta coyuntura era imposible.

El realismo de Reagan no tiene una gran conceptualización doctrinaria sino es más bien pragmático. Para la administración republicana era fundamental terminar con el repliegue estratégico de las dos últimas décadas de distensión que habían sido más útil al aventurerismo y expansionismo 
soviético. Estados Unidos, sostenía que la URSS no es un Estado como cualquier otro, sino uno revolucionario como la Alemania de Hitler (Valdes, 1987, pp. 192-193).

El objetivo era crear un nuevo orden mundial donde los norteamericanos fuesen los dueños omnipotentes del poder dominante. George Bush padre (1988-1992) fue el artífice un poco idealista del nuevo orden mundial que apuntaba a que vencidos los totalitarismos fascistas y marxistas el mundo entraría en un periodo de estabilidad y armonía reduciendo la posibilidad de conflictos, se llegó a decir por parte de algunos intelectuales que la historia se había acabado. Su asesor en política exterior James Baker se orienta hacia un realismo moderado adaptado a la nueva situación de reacomodo internacional con la caída del comunismo y el deterioro del poder soviético.

En el caso del ochenio del gobierno de Bill Clinton (1992-2000), centró su política exterior en puntos ya adoptados por Kissinger, Brzezinski y Baker: Orientar el establecimiento de zonas de orden estable retribuidos por cooperación norteamericana y también usar la coacción, amenaza en el uso de la fuerza, en los casos en que fuera necesario (Kissinger, 1996).

\section{OTROS CASOS DE REALISMO HISTÓRICO}

La mantención del dictador Hosni Mubarak en el gobierno de Egipto durante 30 años es un claro ejemplo de pragmatismo realista pese a los múltiples abusos de un gobierno autoritario y violador de los derechos humanos, pese a ellos reconocía como Estado árabe la existencia de Israel y ello bastaba para darle legitimad internacional a ese gobierno por parte de occidente. Un paso significativo en contra de esta posición política, lo dio el Papa Francisco el jueves 14 de mayo de 2015, al reconocer el Estado Vaticano la existencia del estado Palestino, previo a la canonización de dos santas de medio Oriente, con base en elAcuerdo Básico de entendimiento, firmado el 15 de febrero de 2000.
La elección de los hermanos musulmanes en el 2011 y su probable rompimiento de relaciones con Israel, hicieron que aunque ese gobierno de Morsi tuviera legitimidad democrática de origen su caída fue bien recibida en EEUU y occidente.

La distinta preocupación sobre el conflicto étnico de Yugoeslavia y el de Ruanda en la década de los 80 s del siglo XX, tuvo mucho que ver con la ubicación geopolítica de ambos países y los intereses en juego, una guerra de exterminio entre africanos sin recursos no ameritaba la intervención de alguna potencia occidental, el comportamiento mundial frente a esta masacre africana fue vergonzoso. En cambio, la guerra de los Balcanes ocupo el foco noticioso durante meses pero no de manera morbosa como el conflicto ruandés, sino más bien por su cercanía fronteriza con la Unión Europea y los intereses en juego.

La diferencia entre liberación e invasión también está determinada por quien realiza la acción. Si, Sadam Hussein invade Kuwait no pasa de una violación al derecho internacional, en cambio, sí lo realiza EE.UU., es una liberación a un pueblo oprimido; obvio que para merecer tal liberación debe tener hidrocarburos como petróleo o gas y no mangos ni bananos.

En el tema de los derechos humanos también se ven rezagos de intereses nacionales y realismo frente a la situación de Cuba y China frente a este asunto. EEUU realiza un embargo a la isla caribeña pero no muestra la misma fuerza cuestionadora frente al gigante asiático, no obstante los avances que por mediación del Vaticano se dieron en diciembre de 2014 y que se concretan con la visita del Papa Francisco a la isla en septiembre de 2015 antes de pasar a Washington a reunirse con Obama. La diferencia radica entre un pequeño país con azúcar ron y tabaco a un país superpoblado con un ejército numeroso y armas nucleares que posibilita y explica un tratamiento tan diferenciado frente a la misma situación de vulnerabilidad de derechos fundamentales en ambos países. 
Muchos internacionalistas pensaron que el idealismo no respondía a la coyuntura del sistema internacional y para eso surge como alternativa el paradigma realista como dominante en la interpretación de los hechos internacionales hasta nuestros días. La guerra fría le sirvió como justificación para interpretar los hechos a partir de 1947. El espíritu hobbesiano de la anarquía, el estado de naturaleza y la ley del más fuerte había sido superado por el contrato social de Rousseau que apuntaba al orden la ley y la paz, pero ello no se hizo extensivo a la interpretación de la realidad internacional donde el Estado seguía siendo la suprema unidad política en un sistema anárquico y desigual. El mundo es como una mesa de billar, donde las bolitas chocan de manera normal en un espacio reducido; es por ello que el conflicto es consustancial al sistema internacional. El Estado y el poder se transforman en actor y factor para explicar teoría y práctica internacional.

Morgenthau en su obra cumbre "Politica entre Naciones" destaca la importancia de las leyes inmutables de la naturaleza humana para explicar los devenires del acontecer internacional y el propio paradigma realista. En el acontecer internacional se hacía necesario de manera instrumental ordenar racional y teóricamente los acontecimientos internacionales que sin esta explicación previa aparecían como irracionales e inteligibles por la naturaleza del caos explicado previamente. La teoría debía estar conectada a la forma de actuar y pensar en las relaciones internacionales y sobre los hechos y las decisiones de la política exterior.

\section{CONCLUSIONES}

El poder es el principal elemento regulador que establece criterios de orden en el desorden inherente a la realidad mundial asegurando la perpetuación y seguridad de los estados. El poder está en el ADN humano y en el caso mundial al no existir un poder superior que regule el sistema global los actores estatales recurrirían al poder para conservar la seguridad nacional. La seguridad es una condición deseada universalmente por toda la población y quien se presente como su proveedor y custodio, se hará acreedor al reconocimiento público. Este pensamiento fue influyente para la comunidad anglosajona debido a una aceptación de nuevos valores en la comprensión del sistema internacional tomando como modelo a Estados Unidos, valorar positivamente a las ciencias sociales y el campo de los temas foráneos como objeto de estudio novedoso y también el evidente fracaso y decepción del idealismo representado en la fallida Liga de Naciones y el pensamiento Wilsoniano. Todo esto le dio en el periodo de Guerra Fría gran credibilidad al realismo.

La disyuntiva entre lo correcto y lo efectivo en la sociedad internacional se mantendrá mientras el sistema sea auto coactivo en términos de derecho y no exista un ente de poder supranacional que regule las relaciones entre los Estados de distinto poder nacional. El mecanismo de permanencia en el sistema estará reglado por el poder disuasivo de las armas y un derecho internacional que tenga una coacción orientada y dirigida solo a intereses superiores de unos pocos. Sería muy poco probable la factibilidad de un paradigma distinto al realismo en estas circunstancias.

\section{REFERENCIAS BIBLIOGRÁFICAS}

- Arenal, C. (2002). La teoria de las relaciones internacionales en los arbores del siglo 21. Revista electronica de estudios internacionales., 3.

- Arroyo, P. (1999). Metodologia de las Relaciones Internacionales. Mexico DF: Oxford.

- Carr, E. (1964). An introduction to the study of International Relation. Londres: Harper y Row.

- Cvitanic, F. (2014). Conceptos basicos de relaciones Internacionales. Bogotá: Universidad de La Sabana.

- Kissinger, H. (1996). Diplomacia. Mexico: Fondo de Cultura.

- Oro Tapia, L. (2009). En torno a la noción de realismo político. Enfoques, 15-46.

- Ortiz, E. (2000). El Estudio de las relaciones internacionales. Santiago: Fondo de cultura económica.

- Palacio de Oteyza, V. (2003-2004). La Imagen 
imperial del nuevo orden internacional. CIDOB, 910.

- Peltz, S. (1991). Changing international System. The Wordl balance and power and the USA. En Journal of diplomatic history vol 15 number 1. EEUU: Scholary Ressources inc.

- Rosa, V. d. (2010). Ser o no ser? El realismo politico y el multipolarismo del siglo XXI. Espiral, estudio sobre Estado y Socierdad, 231.

- Sanhueza, R. (2003). El realismo político un denostado desconocido. Teoria y realidad constitucional numero 10-11, 401-402.

- Sen, A. (2009). La idea de la justicia. Bogota: Taurus.

- Uribe Armando, O. (2002). Intervencion norteamericana en Chile. Santiago: Editorial Sudamericana .

- Valdes, S. (1987). Manual de política mundial contemporánea. Santiago de Chile: Andres Bello.

- Vásquez, J. (1994). Relaciones internacionales. México D.F. : Noriega editores.

- Waltz, K. (1988). Teoria de la politica internacional. GEL. 